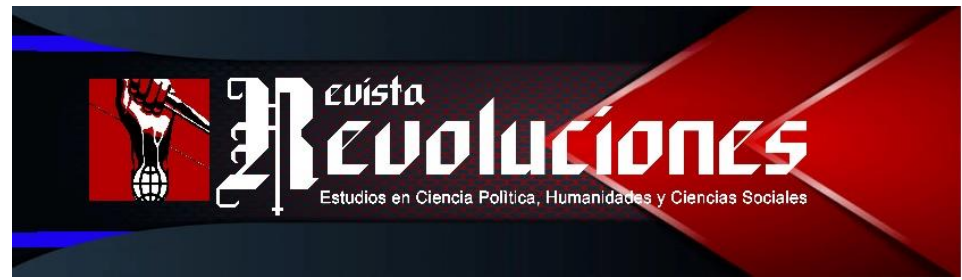

ARTÍCULO ORIGINAL

\title{
NEOCOLONIALISMO EPISTEMOLÓGICO EN LAS CIENCIAS SOCIALES DEL PERÚ DEL SIGLO XXI
}

\section{Epistemological neocolonialism in the Social Sciences of Peru in the $X X I$ century}

\author{
Héctor Cáceres-Bejarano ${ }^{1}$ \\ UNIVERSIDAD NACIONAL MAYOR DE SAN MARCOS \\ PERÚ \\ hector.caceres@unmsm.edu.pe \\ http://orcid.org/oooo-0002-7501-5843
}

DOI: https://doi.org/10.35622/j.rr.2021.04.002

Recibido: 06-III-2021 / Aceptado: 10-IV-2021 / Actualizado: 06-VIII-2021

\section{Resumen}

El neocolonialismo epistemológico en el Perú, y particularmente en las ciencias sociales, como son la arqueología, la antropología, la historia y la sociología; se manifiesta desde sus orígenes e introducción. Esto se debe a que son el efecto del trabajo de diferentes investigadores extranjeros que estudiaron nuestra realidad cultural y social, así como arqueológica e histórica. Así, el desarrollo de nuestras ciencias se reproduce desde los avances científicos y tecnológicos desde los centros científicos y culturales en EEUU y Europa. Esto no ha cambiado mucho hasta el día de hoy, pues nuestro estamento académico recurre a diferentes medios de intercambio cultural para acceder a los últimos adelantos para luego reproducirlos en nuestro país. Sin embargo, ello también implica formas de pensar y actuar, sistemas de creencias y valores; que se han adoptado desde los nuevos enfoques culturales y valorativos dominantes, ejerciéndose o reproduciéndose así, las nuevas formas de neocolonialismo cultural.

Palabras Clave: Perú, neocolonialismo, epistemología, posmodernismo, ciencias sociales.

\begin{abstract}
The epistemological neocolonialism in Peru, and particularly in the social sciences, such as archaeology, anthropology, history and sociology, is manifested from its origins and

${ }^{1}$ Maestrando en Epistemología de las Ciencias y en Arqueología Andina de la UNMSM. Con especialización en Gestión cultural de la Universidad Nacional de Córdova.
\end{abstract}


ISSN: 2710-0499 ISSN-L: 2710-0480

introduction. This is because they are the effect of the work of different foreign researchers who studied our cultural and social reality as well as archaeological and historical. Thus, the development of our sciences is reproduced from the scientific and technological advances from the scientific and cultural centers in the USA and Europe. This has not changed much to this day, since our academic establishment resorts to different means of cultural exchange to access the latest advances and then reproduce them in our country. However, this also implies ways of thinking and acting, systems of beliefs and values, which have been adopted from the new dominant cultural and value approaches, thus exercising or reproducing new forms of cultural neocolonialism.

Keyword: Peru, neocolonialism, epistemology, postmodernism, social sciences.

\section{INTRODUCCIÓN}

El tema del neocolonialismo² y específicamente la decolonialidad o descolonización, ha tenido y tiene una gran relevancia para los países considerados periféricos y particularmente en Latinoamérica. Así, a lo largo de los últimos cincuenta años se han desarrollado diferentes perspectivas reflexivas sobre el fenómeno del neocolonialismo y las denominadas formas de emancipación. Así tenemos a la teoría de la dependencia y la teoría de la liberación como corrientes de pensamiento que intentaron explicar y movilizar esfuerzos políticos, económicos y sociales en aras de un cambio emancipatorio; temas como la modernidad, la racionalización, la secularización y la identidad cultural han sido materia de discusión sobre sus procesos, dinámicas y cambios. En tal sentido, Altbach (1971), sostenía que el neocolonialismo se refiere a la influencia continua de los países desarrollados tanto en los sistemas económicos como en las políticas educativas al igual que en la cultura, el mundo intelectual y diferentes áreas de desarrollo de su interés, no habiendo un control político directo. Para Haag (2011) existen formas sutiles y variadas de continuar con la dependencia. Estas formas pueden darse desde los sectores educativos y culturales (citado por Macías, 2015).

De tal modo que, el neocolonialismo es un sistema de dependencia en donde los países desarrollados y sus centros de dominación económica, política y cultural ejercen su influencia sobre las sociedades o países subdesarrollados. Esto se ejerce de diferentes formas, tanto en los espacios educativos y los valores que configuran la subjetividad de las personas, en las

\footnotetext{
2 Es importante diferenciar los términos poscolonialismo, decolonialidad y neocolonialismo. En ese sentido, para Robert J.C. Young, profesor de New York University, el poscolonialismo es el período posterior a un régimen colonial o imperialista cuyo dominio era directo sobre la sociedad o pueblo sojuzgado. Para Mignolo (2007), el pensamiento decolonial surgió como contrapartida ante lo moderno y colonial, y se refiere a la racionalidad moderna que permea las expresiones culturales y del conocimiento, siendo primero el griego y el latín; y después las seis lenguas imperiales europeas modernas que estructuran sus marcos impositivos linguísticos y culturales. En el caso del neocolonialismo, este puede entenderse según Kwame Nkrumah como un sistema en el cual el Estado bajo influencia neocolonial es formalmente independiente y con soberanía, pero que todavía está bajo cierto control político y económico desde el exterior. En esta dependencia ciertamente las élites políticas y económicas del país neocolonizado cumplen un rol que mantiene las relaciones que favorecen a los países dominantes, y así se reciben beneficios políticos, económicos y culturales (Macías, 2015).
} 
relaciones comerciales, a nivel científico, tecnológico y cultural; generándose relaciones asimétricas de beneficios económicos y políticos mediante arreglos institucionales, promoviendo simultáneamente una transculturización y una falsa conciencia o rasgos de alienación cultural (Martín Serrano, 1977; Vargas, 2005, Britto, 2012; Quijano, 2014, Menéndez, 2018).

Según Lander (2000), es importante considerar el contexto de la sociedad liberal industrial, la cual se impone como el orden social deseable o incluso como único posible. En esta concepción, nos encontramos hoy en un punto de llegada: sociedad sin ideologías, modelo civilizatorio único, globalizado, universal, que hace innecesaria la política, en la medida en que ya no hay alternativas posibles a ese modo de vida. Así, las diferentes dimensiones políticas, económicas y sociales que se encuentran enmarcadas en el sistema económico liberal y/o neoliberal, el sistema político democrático con todas sus contradicciones y sus debilidades institucionales, y el escepticismo posmoderno son los aspectos que configuran nuestra realidad en estas primeras décadas del siglo XXI.

Al respecto Enrique Dussel (2015) en la entrevista "La filosofía europea no es universal" plantea aspectos muy interesantes sobre el tema, considera que la descolonización epistemológica ha tomado mucha fuerza, y que en ello han contribuido personajes como Aníbal Quijano. Este en sus diferentes textos describe y denuncia nuestra situación de colonialidad y dependencia, así tenemos: Colonialidad del poder, eurocentrismo y América Latina (2000), Colonialidad del poder y clasificación (2000), La crisis del horizonte de sentido colonial/moderno/eurocentrista (2010), Colonialidad del poder, globalización y democracia (2014) y otros. Esta problemática contempla lo que se denomina como pensamiento universal, que no es sino el eurocentrismo, pero dentro de un mundo globalizado.

Dussel (2015) nos describe también sus impresiones sobre el tema dándonos una perspectiva histórica, nos indica que hacia fines de los años sesenta e inicios de 1970 Augusto Salazar Bondy (1968) hizo una pregunta crucial: ¿Es posible una filosofía de nuestra América?, la respuesta le era negativa, pues somos colonias; en cambio el mexicano Leopoldo Zea consideraba que no era posible más bien por otra razón y esta era porque la filosofía es universal y siempre se practicó así. Dentro de este debate terció la filosofía de la liberación, la cual afirma que siempre ha existido una filosofía latinoamericana, pero esta nunca fue reconocida mundialmente y ciertamente los filósofos latinoamericanos no suelen aparecer en la historia de la filosofía universal. Por ello Dussel considera que esto nos debe llevar a cambiar de mentalidad, buscando superar la modernidad en una nueva sociedad poscapitalista y ecológica a la que define como transmodernidad, para diferenciarse de la inclusión del capitalismo que conlleva el posmodernismo. En ese sentido, el socialismo tal como se conocía en sus raíces ha quedado desfasado por ser también antiecológico y no ha considerado la liberación de la mujer, ni a la naturaleza ni al adulto mayor (ex URSS, China, entre otros). Dussel así reivindica a Marx, pero cuestiona las formas como se conducen los movimientos socialistas. 
Dussel también afirma que la crítica decolonial no implica descartar todo lo logrado por Europa sino - más bien - rescatar de cada civilización lo fuerte, interesante, crítico y desarrollarlo en la actual realidad. Respecto a América Latina, considera que en esta existe una élite criolla y moderna, además racista - como sostiene Aníbal Quijano -, pero igualmente colonial. Por lo que aún están pendientes la descolonización de la ciencia, la ideología y la economía. Por otro lado, desde una perspectiva metodológica y epistemológica se debe reconocer la influencia de los países desarrollados, pues es evidente que prácticamente casi toda la producción científica en las Ciencias Sociales latinoamericanas tiene una clara influencia europea y norteamericana.

Según Denzin y Lincoln (2005), las naciones colonizadoras abordaron disciplinas particularmente como la sociología y la antropología para producir conocimiento acerca de mundos ajenos al suyo o extranjeros y así extender sus imperios o dominios. En estos procesos del proyecto colonial, estas disciplinas aportaron significativamente en el desarrollo de la investigación en ciencias sociales; y ciertamente generaron una reacción negativa de la palabra colonización. En cuanto a la sociología, el trabajo de la "Escuela de Chicago" en las décadas de 1920 y 1930 estableció la importancia de la investigación cualitativa para el estudio de la vida de grupos humanos. Así también en antropología, durante el mismo período, los avances de investigación llevados a cabo por Boas, Mead, Benedict, Bateson, Evans, Pritchard, Radcliffe-Brown, y Mallinowski trazaron el perfil del método de trabajo de campo (Grupta \& Ferguson, 1997; Stocking, 1986, 1989). Así, particularmente en las metodologías cualitativas, todas ellas tienen una impronta norteamericana o eurocentrista, siendo muy relevantes para las actuales corrientes posmodernistas ciertamente. Pero cabe mencionar en cuanto a las metodologías cuantitativas, estas también poseen dicha influencia desde los inicios de su desarrollo.

\section{METODOLOGÍA}

El presente trabajo se enmarca dentro del enfoque cualitativo, haciendo una revisión bibliográfica dentro del desarrollo histórico de las ciencias sociales en el Perú; para ello se hace un recorrido de los diferentes campos de investigación de las ciencias sociales, estos son la arqueología, la antropología, la historia y la sociología. Además, se hace una selección de tesis, siendo una muestra conformada por todas aquellas que se encuentran en los archivos digitales de los últimos siete años de las unidades de posgrado en ciencias sociales, particularmente en estudios de género; y que se desarrollan en las Universidades más importantes de Lima - Perú, estas son la Universidad Nacional Mayor de San Marcos y la Pontificia Universidad Católica del Perú. Luego se hace un análisis descriptivo de sus contenidos epistemológicos y metodológicos. 


\section{DESARROLLO}

\section{Desarrollo del pensamiento neocolonial en el Perú}

El neocolonialismo epistemológico en el Perú se traduce en la influencia de las corrientes de pensamiento foráneo en diferentes campos del conocimiento y las ciencias, así como por la relevancia preponderante de los centros de desarrollo de ciencia, conocimiento y tecnología de los países más desarrollados. Lo cual se refleja respecto de los saberes, así como del hacer en cuanto a los procesos, desarrollo y legitimación del conocimiento. Ello también se observa en las percepciones de la ciencia y las aplicaciones de la tecnología. Puede decirse que hay todo un conjunto de aproximaciones, normas, procedimientos, principios y valoraciones que permean las formas de pensar y actuar en las diferentes materias o campos del conocimiento. Asimismo, cabe mencionar las redes de relaciones sociales que se van generando a lo largo del tiempo entre las diferentes instituciones del extranjero y de nuestro país. Y desde allí a los diferentes ámbitos de la sociedad civil y del Estado.

\section{El neocolonialismo en las ciencias sociales en el Perú}

Antes que nada, es importante llamar la atención sobre la complejidad de nuestra sociedad y sus particulares características. En ese sentido, debe decirse que el Perú es un país pluricultural y multirracial con un modelo de desarrollo principalmente exportador de materias primas (minería y agricultura) y es sobre todo importador de productos, conocimientos y tecnologías. Desde inicios de la república - hace casi doscientos años - este modelo se ha mantenido, ya sea por la complicidad o el descuido de las élites criollas políticas, económicas y sociales. Por lo que se ha continuado con una dependencia de los centros de desarrollo económico y cultural de Europa en un principio y después de los EEUU. Esta dependencia no fue muy diferente en lo que respecta al desarrollo científico y tecnológico. Así, nuestras instituciones académicas y de enseñanza han estado reproduciendo los modelos de aprendizaje, conocimiento, teorías y tecnología foráneas. Es interesante observar que a lo largo de nuestra emergente nación como república fueron también científicos extranjeros quienes pusieron los gérmenes para el desarrollo de los campos de las ciencias sociales en nuestro país.

En lo que respecta al desarrollo de las ciencias sociales en el Perú, al igual que en los otros campos del saber, estos fueron importados. Tanto la antropología, la sociología, la historia y la arqueología fueron espacios de estudio e investigación introducidos en el país por estudiosos extranjeros interesados en nuestra realidad. Así tenemos, por ejemplo, según Manuel Burga (2005), que los primeros estudios que pueden caracterizarse como modernos y sistemáticos, tanto de historia como de antropología en la historiografía peruana los encontramos en la obra de Heinrich Cunow (1862-1936).

Entre estas obras están Las comunidades de Aldea y Marca del antiguo Perú de 189o, El sistema de parentesco peruano y las comunidades gentilicias de los Incas de 1891 y La 
ISSN: 2710-0499 ISSN-L: 2710-0480

Organización social del imperio de los Incas de 1896. Burga llama la atención sobre el hecho que algunas o muchas investigaciones fueron utilizadas con fines políticos. Así, en el caso de la obra sobre La organización social del imperio de los incas, su subtítulo Investigación sobre el comunismo agrario en el Antiguo Perú ha sido citado muchas veces por escritores peruanos socialistas con claros fines políticos; Cunow fue también un intelectual socialista, muy crítico del fascismo de su época.

Así también tenemos, nos dice Burga (2005), el caso de Paul Rivet (1876-1958), quien fue antropólogo, lingüista y diputado socialista; que estaba muy interesado en la historia, fundador del Musée de l'Homme de París. Paul Rivet visitó desde 1930 el Perú, se relacionó con muchos estudiosos peruanos y fomentó los estudios antropológicos, históricos y lingüísticos. Rivet en su obra Los orígenes del hombre americano (1943) expuso dos teorías histórico-antropológicas con una amplia difusión y aceptación en el Perú: la inmigración asiática y polinésica tardía que pobló América y el autoctonismo de las culturas indígenas americanas. La segunda teoría, que provenía de la arqueología, le permitió un buen diálogo con el arqueólogo peruano Julio C. Tello y también con la moderna arqueología peruana y andina en general. (Burga, 2005).

Y otro ejemplo que nos expone Burga (2005) es el de Alfred Métraux (1902-1963), quien en su obra Les Incas (1961), populariza las conclusiones de las investigaciones de John V. Murra (etnohistoriador ucraniano naturalizado estadounidense), y que contribuyó a difundir ampliamente la idea de que los campesinos quechuas actuales en estado de miseria y que estuvieron bajo explotación feudal del sistema de haciendas, eran realmente los detentadores, re-inventores y herederos de la cultura material y espiritual que poseyó el hatun runa (mayoría social) de la época Inca.

En los últimos cincuenta años en los campos de la historia, la antropología y la etnohistoria ha habido un desarrollo que se ha caracterizado por el trabajo coordinado entre estudiosos peruanos y extranjeros (pero siempre con metodologías importadas).

Así ocurre, según Burga (2005), con la nueva etnohistoria andina realizada por extranjeros como John V. Murra, John H. Rowe y R. Tom Zuidema y los peruanos Waldemar Espinoza, Franklin Pease y María Rostworowski; etnohistoria que desarrolla una imagen de las sociedades prehispánicas. Por un lado, John H. Rowe abordó el tema desde la arqueología, la etnohistoria y la historia del arte. John V. Murra comenzó estudiando a los campesinos de Otavalo y terminó proponiendo el modelo recíproco-redistributivo para entender la especificidad de la organización económica del Estado Inca. R. T. Zuidema comenzó estudiando a las comunidades campesinas de España, luego abordó el estudio de las regiones andinas actuales e históricas, y propuso el modelo estructural para entender la organización social, política y ritual del Cusco.

En lo que respecta a la arqueología, la situación no fue muy diferente, la disciplina fue importada y constituida en nuestro país por la contribución de las expediciones arqueológicas 
alemanas en el siglo XIX. Así, según Elmo León (2013), la arqueología alemana en el Perú tuvo tres momentos o etapas:

- Desde fines del s. XIX.: Focalización en la documentación y publicación: alfarería, etnobotánica. Estos fueron los trabajos pioneros.

- Las primeras décadas del s. XX: Interés en los ceramios con representaciones iconográficas (nazca, mochica) además de restos óseos y momias. Estudios en laboratorio y trabajos de campo.

- Y la continuidad de líneas de estudio, pero siguiendo los análisis iconográficos con métodos modernos: uso del ADN, 3D, etc.

Se puede decir que entre los años 1875 - 1910 se inició el descubrimiento de la arqueología peruana. Entre los primeros investigadores alemanes dedicados a hacer estudios en el Perú, según León (2013), tenemos a Wilhem Reiss y Alphons Stuebel: Ancón (1875). Sin embargo, el personaje más importante de la arqueología alemana en el Perú es Max Uhle (1856 - 1944), se le considera el padre de la arqueología peruana. Uhle llegó a Sudamérica en 1892, excavó y estudió en diferentes lugares (Ica, Nazca, Moche, Pachacamac, Tiahuanaco). Su libro es el primer trabajo estratigráfico de América "Pachacamac" (1903). Uhle da inicio a una nueva etapa de ensayo científico: cronología, contextualización de hallazgos, caracterización cultural y defensa del patrimonio arqueológico. Además, hizo el primer cuadro de cronología prehispánica peruana e introdujo el concepto de "Horizonte". Se trató de un personaje interdisciplinario que anduvo entre la etnobotánica, zooarqueología, lingüística, etnohistoria, arqueoastronomía y etnología.

Sin embargo, aparte de Max Uhle, tenemos al médico y antropólogo peruano nacido en Huarochiri Julio C. Tello (1880 - 1947), quien se convirtió en todo un referente de la arqueología peruana. Es también considerado por muchos, especialmente desde el nacionalismo, como padre de la arqueología peruana por todo su encomiable trabajo realizado. Hizo muchos descubrimientos, especialmente en las culturas Chavín y Paracas, impulsó y creó el Museo de Arqueología, Antropología e Historia del Perú. Pero ciertamente hay que mencionar que Tello se formó primero como médico, habiendo estudiado en la facultad de San Fernando de la Universidad Nacional Mayor de San Marcos. Luego incursionó como profesional en el campo de la antropología y la arqueología, pues hizo un posgrado en EEUU en la Universidad de Harvard y obtuvo el grado de Master of Arts con especialización en antropología; después hizo estudios en la Universidad de Berlín, donde asimiló las corrientes teóricas difusionistas que estaban en boga (Tantaleán, 2016).

Posteriormente ha habido otras expediciones de extranjeros también alemanes, norteamericanos, italianos y polacos interesados en nuestro pasado; quienes han dado forma al desarrollo de la arqueología en el Perú. Por otro lado, nuestros profesionales al igual que en otros campos de investigación, también optan por seguir estudios en el exterior, especialmente en universidades norteamericanas o europeas; esto con el fin de formarse y 
asimilar lo último del desarrollo científico y metodológico del campo, desde los centros hegemónicos científicos y culturales.

En lo que respecta al campo de la sociología en el Perú, según Julio Mejía (2005), esta surgió como cátedra universitaria en la Universidad Nacional Mayor de San Marcos en 1896. Sin embargo, esta cátedra fue la expresión intelectual más conservadora y civilista de la generación del novecientos. Por lo que dicha cátedra de sociología formaba parte de esas tendencias oligárquicas y clientelísticas. En ese contexto fue Mariano H. Cornejo, el que bajo la influencia de Herbert Spencer, publica el texto Sociología General en dos tomos (1908 y 1910), y expone de manera sistemática el pensamiento sociológico europeo. Pero esta obra nos dice Mejía (2005), se caracterizaba por exponer las interpretaciones teorizantes sobre la sociedad en general y estaba muy dependiente de la discusión europea. Cornejo al igual que otros intelectuales de su época asumieron una posición eurocéntrica y positivista. Empero, la sociología más bien se institucionaliza como profesión con la fundación del Instituto de Sociología en la Universidad Nacional Mayor de San Marcos en 1956. Y luego, en la década del sesenta se crean las principales escuelas en el país, siendo una etapa caracterizada por la tensión constitutiva entre dos modelos de hacer sociología: por un lado, el estructuralfuncionalismo que fue introducido en el Perú por el francés Francois Bourricaud y por otro lado el marxismo; siendo esta la corriente más resaltante y que define la sociología del siglo XX junto con la teoría de la dependencia.

Pero en los años ochenta nos dice Mejía (2005), se inicia una nueva etapa en el desarrollo de la sociología en el Perú, que al igual que en América Latina, se caracteriza por transcurrir de procesos revolucionarios a democráticos; siendo este el tema de debate y desarrollo en la investigación social. A esta etapa se le ha denominado el "giro constructivista", que es lo equivalente en las ciencias sociales al "giro lingüístico" o hermenéutico desarrollado y proveniente de la filosofía. Esto es definido en el sentido de que las cosas no son realmente como son los hechos sociales objetivos, sino más bien cómo son interpretados o construidos por los sujetos. Así, la sociología se reorienta hacia La construcción social de la realidad, que es el título de la obra de Berger y Luckmann (1966) y que describe estos procesos. Guillermo Nugent lo denomina como el desarrollo del "paradigma del mundo de la vida". Y, ciertamente, es el método cualitativo el que se ha impuesto con un desarrollo extensivo en la sociología y las ciencias sociales en general.

En las últimas décadas aparecen los enfoques posmodernos, entre ellos sobre el género y el debate por las transformaciones globales; como por ejemplo la descolonización del saber de Carolina Ortiz (2003) y otros textos como Género, colonialidad del poder, conocimiento y las políticas de igualdad hoy. Seducción, género y poder en Dioses y hombres de Huarochirí y la Nueva crónica y buen gobierno (2011), Proceso de descolonización del imaginario y del conocimiento en América Latina. Poéticas de la violencia de la crisis. (2004); así también la ya mencionada colonización del poder y la clasificación social de Aníbal Quijano (2000), tanto como la problemática del desarrollo dentro de la perspectiva latinoamericana entre otros (Mejía, 2005). 


\section{Neocolonialismo en el mundo académico en el Perú del siglo XXI}

Como se ha visto, el Perú ha estado desde su constitución como República, bajo la influencia eurocéntrica y luego norteamericana. Ello también se ha manifestado en el desarrollo de sus ciencias sociales. Hasta hace unas décadas la influencia epistemológica provenía del positivismo, el estructuralismo y después del marxismo. Este se impartía, por ejemplo, en diferentes universidades como la Universidad Nacional Mayor de San Marcos y la Universidad Nacional Enrique Guzmán y Valle; con diferentes cursos como materialismo dialéctico, materialismo histórico y otros. Mientras que en las universidades particulares como la Universidad de Lima y la Universidad del Pacífico la enseñanza de los materialismos citados estaba vetada, prefiriendo enfocar su enseñanza desde las perspectivas liberales o neoliberales.

Pero, desde hace veinte y cinco años aproximadamente, la influencia posmoderna ha ido creciendo dentro de las ciencias sociales en el Perú, primero con los intercambios o becas de estudios en el extranjero otorgadas a los estudiantes de pregrado y postgrado. Dichos egresados fueron formados con el pensamiento débil o posmoderno, después regresaron al Perú a impartir cursos en diferentes instituciones. Los egresados de dichos estudios ahora son técnicos o funcionarios públicos y de la sociedad civil en diferentes niveles, plasmando mediante políticas públicas o programas y proyectos, el sistema de creencias posmoderno. Por ello no sorprende el crecimiento de diferentes organizaciones sociales y movimientos con ese perfil.

Hacer un posgrado en alguna institución de EEUU y Europa es algo que cualquier estudiante podría desear o aspirar. Empero, es importante observar el impacto de estos programas de estudios e intercambios en las respectivas sociedades y bajo que propósitos se promueven.

En nuestro país puede verse la influencia exterior y particularmente de las potencias, en cuanto a sus sistemas de conocimientos, creencias, ciencia, tecnología y valores en los diferentes cuadros de profesionales que se han formado en sus respectivas instituciones.

También encontramos dicha influencia en la forma de impartir la enseñanza y orientar a los educandos, ya sea promoviendo cierto tipo de ideas o en las formas de hacer la investigación (incluyendo la asesoría de las tesis de investigación). Es así como puede observarse los indicadores de las influencias de diverso tipo, en este caso del sistema de creencias y valores epistemológicos posmodernos dentro de las ciencias sociales, particularmente en los estudios de género. Por ejemplo, se puede observar algunas tesis de investigación de maestría de los últimos siete años en la UNMSM y la PUCP. Y podemos encontrar una clara tendencia hacia el uso del enfoque cualitativo y crítico, el estudio de casos y también manifiestos compromisos políticos de las investigaciones.

Maestría de Estudios de Género PUCP Repositorio. (2013 - 2020)

Revista Revoluciones -14- Vol. 3, No 4 (2021), pp. 6-25

Esta obra está bajo una licencia internacional Creative Commons Atribución 4.0. 
ISSN: 2710-0499 ISSN-L: 2710-0480

\begin{tabular}{|c|c|c|c|}
\hline & TESIS & AUTOR y AÑO & CONTENIDO METODOLÓGICO \\
\hline $\mathbf{1}$ & $\begin{array}{l}\frac{\text { Masculinidad }}{\text { es en los }} \\
\begin{array}{c}\text { conflictos } \\
\text { socioambient }\end{array} \\
\frac{\text { ales: el caso }}{\text { conga }}\end{array}$ & $\begin{array}{l}\text { Ormachea } \\
\text { Choque, Ivan }\end{array}$ & $\begin{array}{l}\text { Metodología cualitativa } \\
\text { Análisis del discurso de dos videos } \\
\text { Estudia la masculinidad dentro de las situaciones de conflicto (especialmente en la política) } \\
\text { En breve, esta investigación aportará al debate en cuanto a los conflictos socioambientales } \\
\text { utilizando la perspectiva de los estudios de género, más específicamente, desde el campo de } \\
\text { la masculinidad, visibilizando la característica de género de estos conflictos, que implica no } \\
\text { solo el protagonismo de los varones sino comprender cómo se produce el encuentro de } \\
\text { diferentes identidades masculinas - que provienen de sistemas de género diferentes- } \\
\text { promovidas por el diálogo, como mecanismo de gestión de conflictos, y las negociaciones } \\
\text { de poder que plantean los actores involucrados a partir del capital masculino que traen a } \\
\text { las mesas de diálogo (p. 11-12) } \\
\text { El marco teórico de la presente investigación se estructura en base a tres enfoques. El } \\
\text { primero de ellos referido a sistema de género, género y patriarcado (...). En segundo lugar, } \\
\text { introduciremos el enfoque del análisis crítico del discurso (ACD) que considera al discurso } \\
\text { como una práctica social (Fairclough 1992), el cual será muy útil para, desde el lenguaje, } \\
\text { entender cómo se enuncia la identidad de género, cómo se negocian las relaciones de género } \\
\text { entre los protagonistas de la mesa de diálogo del proyecto minero Conga, } \\
\text { fundamentalmente relaciones de poder, y cómo lo identitario y relacional se adscribe en un } \\
\text { sistema de creencias y conocimientos permeado por la ideología y un discurso hegemónico, } \\
\text { que plantea relaciones de dominación y subordinación (...). El tercer y último eje se referirá } \\
\text { al diálogo y a la negociación, como mecanismos de gestión de conflictos socioambientales, } \\
\text { los cuáles serán presentados en clave de género ... (pp. 26 - 27) } \\
\text { Referentes conceptuales. } \\
\text { Sistemas de género, identidad de género, relaciones de género, patriarcado. }\end{array}$ \\
\hline 2 & $\begin{array}{c}\frac{\text { Reconstrucció }}{\text { n de las }} \\
\begin{array}{c}\text { memorias } \\
\text { colectivas de }\end{array} \\
\frac{\text { los grupos de }}{\text { lesbianas }} \\
\frac{\begin{array}{c}\text { feministas de } \\
\text { Lima en el }\end{array}}{\text { periodo 1984- }} \\
\underline{2014}\end{array}$ & $\begin{array}{l}\text { Rodríguez } \\
\text { Pinedo, Esther } \\
\text { Año } 2017\end{array}$ & $\begin{array}{l}\text { Enfoque cualitativo } \\
\text { Entrevistas (9) } \\
\text { Análisis de textos } \\
\text { Además, esta tesis, también quiere ser un intento de visibilización y transmisión de las voces } \\
\text { y acciones de sujetas subalternizadas en una sociedad patriarcal, heteronormativa, } \\
\text { religiosa-conservadora y jerárquica como la peruana; la cual sanciona la existencia de las } \\
\text { lesbianas a través de la invisibilización, la estigmatización y la violencia. Asimismo, debo } \\
\text { explicitar que soy activista de uno de los grupos de lesbianas feministas de } \\
\text { Lima y como integrante de esta colectividad, me interesa visibilizar su } \\
\text { existencia, dar a conocer su proceso de conformación, sus acciones } \\
\text { reivindicativas y sus propuestas; así como, sus contradicciones, limitaciones } \\
\text { y heterogeneidad. Por esta militancia lésbica feminista, que configura mi } \\
\text { postura política y mis intereses académicos, soy consciente que debo } \\
\text { mantener una perspectiva epistemológica vigilante y crítica con respecto a las } \\
\text { memorias colectivas que voy a recoger. Esta investigación pretende registrar la } \\
\text { mayor cantidad de voces y miradas de sus protagonistas, incluso de aquellas con las cuales } \\
\text { he tenido y tengo diferencias personales y políticas (p. 11) } \\
\text { Referentes conceptuales: } \\
\text { Feminismo, patriarcalismo, dominio heteronormativo } \\
\text { INTERÉS POLÍtico }\end{array}$ \\
\hline 3 & $\begin{array}{l}\text { Participación } \\
\text { y } \\
\text { representació } \\
\text { n subjetiva de } \\
\text { mujeres } \\
\text { organizadas } \\
\text { en contextos } \\
\end{array}$ & & $\begin{array}{l}\text { Enfoque cualitativo } \\
\text { Entrevistas semiestructuradas (11) } \\
\text { Metodología "dialógica y participativa" } \\
\text { Se aborda la situación de la mujer y su inclusión igualitaria. } \\
\text { Desde la perspectiva de género, interesa particularmente ver las posibilidades de una } \\
\text { inclusión democrática y diferenciada. La cual se concretiza tanto por las oportunidades en } \\
\text { el entorno, como por las propias capacidades de acción personal y colectiva de las mujeres }\end{array}$ \\
\hline
\end{tabular}




\begin{tabular}{|c|c|c|c|}
\hline & $\begin{array}{l}\text { de conflicto y } \\
\text { postconflicto }\end{array}$ & $\begin{array}{l}\text { Peña Romero, } \\
\text { Elena Claudia } \\
\text { Año } 2017\end{array}$ & $\begin{array}{l}\text { (Tubino Romero y Gonzales de Olarte, 2014). El tema de la inclusión es crucial para ver si } \\
\text { las mujeres están ejerciendo una participación efectiva; si son escuchadas y reconocidas de } \\
\text { manera igualitaria, valorando sus perspectivas y aportes (p. 10) } \\
\text { En un país de mucha exclusión social como el nuestro, es importante conocer cómo se están } \\
\text { dando las condiciones para una participación efectiva e inclusiva en los sectores más } \\
\text { afectados por los conflictos. Identificar las posibilidades o dificultades en el } \\
\text { ejercicio de su participación, puede contribuir al desarrollo de acciones para } \\
\text { su fortalecimiento, tanto en las políticas de inclusión social, como en el trabajo } \\
\text { psicosocial comunitario; para que las mujeres hagan escuchar más sus voces } \\
\text { y aporten desde su perspectiva en sus comunidades (p. 11) } \\
\text { Estas experiencias, en las que también me he indignado junto con ellas, me he conmovido, } \\
\text { me he frustrado, y a la vez me he fortalecido con su ejemplo, sus luchas y su fraternidad; } \\
\text { han hecho que vea la importancia de atender la problemática de los conflictos sociales que } \\
\text { afectan a nuestras comunidades, entendiéndolo con un enfoque histórico-social y de } \\
\text { género. Reconociendo situaciones de exclusión y de violencia que se repiten, pero también } \\
\text { viendo las potencialidades y contribuciones del accionar político de las } \\
\text { mujeres (p. 12) } \\
\text { Referentes conceptuales: } \\
\text { Roles de género, violencias y desigualdades de género } \\
\text { INTERÉS POLÍTICO }\end{array}$ \\
\hline 4 & $\begin{array}{c}\begin{array}{c}\text { Violación y } \\
\text { masculinidad: }\end{array} \\
\frac{\text { representacio }}{\text { nes de lo }} \\
\begin{array}{c}\text { masculino en } \\
\text { varones }\end{array} \\
\begin{array}{c}\text { recluidos por } \\
\text { ejercer }\end{array} \\
\begin{array}{c}\text { violencia } \\
\text { sexual en el }\end{array} \\
\begin{array}{c}\text { establecimien } \\
\text { to }\end{array} \\
\text { penitenciario } \\
\text { de Cañete }\end{array}$ & $\begin{array}{l}\text { García Vivar, } \\
\text { Ruth Alicia } \\
\text { Año } 2017\end{array}$ & $\begin{array}{l}\text { Tipo exploratorio } \\
\text { Enfoque cualitativo } \\
\text { Entrevistas (4) } \\
\text { Técnicas de asociación libre de palabras, relato de vida } \\
\text { Análisis de la construcción de la masculinidad de violadores varones en prisión. } \\
\text { Esta investigación aborda las representaciones de lo masculino expresadas por varones } \\
\text { privados de su libertad por agredir sexualmente mujeres mayores de edad. Asimismo, } \\
\text { analiza sus explicaciones de la violencia sexual con el fin de entender en qué se sustenta el } \\
\text { ejercicio masculino de la misma para mantener y/o restaurar el estatus. (...) Entre los } \\
\text { hallazgos de la investigación, se encuentra que estos varones han internalizado los } \\
\text { mandatos del modelo referente de masculinidad, el cual los dignifica frente a sí mismos y } \\
\text { los demás. Estos mandatos comprenden el acatamiento a los códigos de la } \\
\text { heteronormatividad, el rechazo de la homosexualidad y la desvalorización de la mujer. } \\
\text { También, se encuentra que los reclusos creen que una víctima de violación puede ser un } \\
\text { niño ouna niña, mas no una mujer adulta. Para ellos, un violador es una persona enferma; } \\
\text { mientras que las mujeres que denuncian ser víctimas de violación son representadas } \\
\text { mediante la figura de la otra, la mujer de la calle. Esta imagen permite que los agresores } \\
\text { nieguen su responsabilidad. Las explicaciones al ejercicio de la violencia (fisica y sexual) } \\
\text { brindadas por los reclusos se vinculan a la desvalorización de la mujer y a la fuerza de los } \\
\text { mandatos que los torna en presas de símismos ante la posible exposición del carácter frágil } \\
\text { de su masculinidad. Estos fenómenos se enmarcan en un contexto en donde las mujeres } \\
\text { logran ocupar espacios tradicionalmente dominados por los hombres. El agresor sexual } \\
\text { sigue siendo alguien cercano al entorno de la víctima, la cual generalmente fue atacada en } \\
\text { situaciones de vulnerabilidad (p. 2) } \\
\text { Referentes conceptuales: } \\
\text { Violencia sexual, dominio masculino y heteronormativo, } \\
\text { INTERÉs POLíTico (acusación de la dominación heteronormativa) }\end{array}$ \\
\hline 5 & $\begin{array}{l}\frac{\text { Representacio }}{\text { nes sociales }} \\
\frac{\text { de la }}{\text { maternidady }} \\
\underline{\text { los }}\end{array}$ & & $\begin{array}{l}\text { Enfoque cualitativo } \\
\text { Dos entrevistas grupales (7) } \\
\text { Entrevistas individuales (10) } \\
\text { Estudio de la relación entre la maternidad y la femeneidad. }\end{array}$ \\
\hline
\end{tabular}


ISSN: 2710-0499 ISSN-L: 2710-0480

\begin{tabular}{|c|c|c|}
\hline $\begin{array}{c}\frac{\text { significados }}{\text { que le asignan }} \\
\frac{\text { las mujeres }}{\text { jóvenes }} \\
\frac{\text { universitarias }}{\text { de estratos }} \\
\frac{\text { medios bajos }}{\text { de Lima }} \\
\text { Metropolitana } \\
\underline{\text { en la }} \\
\underline{\text { construcción }} \\
\underline{\text { de la }} \\
\begin{array}{c}\text { feminidades e } \\
\text { identidades }\end{array} \\
\text { femeninas }\end{array}$ & $\begin{array}{l}\text { Cieza Guevara, } \\
\text { Kelly Luzlinda } \\
\text { Año } 2016\end{array}$ & $\begin{array}{l}\text { Bajo este contexto, esta investigación busca profundizar en los cambios sucedidos en las } \\
\text { representaciones de la maternidad. Esta tiene un lugar central en las identidades } \\
\text { femeninas y ha sido construida como "devenir natural", lo que genera que se considere el } \\
\text { espacio doméstico como propio y único de las mujeres (...) Desde los estudios de género, } \\
\text { autoras como Beauviour (1999), Chodorow (1989) y Badinter (1981) han planteado la } \\
\text { maternidad como una construcción cultural y han cuestionado su naturaleza, dimensión } \\
\text { instintiva e idealización como signos de opresión del sistema patriarcal hacia los cuerpos } \\
\text { de las mujeres. Este cuestionamiento evidencia los cambios que ha tenido la noción de } \\
\text { maternidad en la historia (p. 9) } \\
\text { Referentes conceptuales: } \\
\text { Construcción social y cultural, sistema patriarcal. Teoría, enfoque o ideología de género. }\end{array}$ \\
\hline
\end{tabular}

Cuadro 1: Elaboración propia

\begin{tabular}{|c|c|c|c|}
\hline \multicolumn{4}{|c|}{ Tesis de Maestría de Género y Desarrollo Cybertesis UNMSM (2013 - 2020) } \\
\hline & TESIS & AUTOR y AÑO & CONTENIDO METODOLÓGICO \\
\hline $\mathbf{1}$ & $\begin{array}{c}\frac{\text { Las Formas y }}{\text { colores de los }} \\
\frac{\text { cuerpos en el }}{\text { cotidiano de }} \\
\begin{array}{c}\text { mujeres } \\
\text { cooperativistas }\end{array} \\
\frac{\text { de la selva }}{\text { central: }} \\
\text { persona, } \\
\text { economía social } \\
\text { y política. }\end{array}$ & $\begin{array}{l}\text { Pérez Alva, Ela } \\
\text { Dorena. } \\
\text { Año } 2020\end{array}$ & $\begin{array}{l}\text { Enfoque cualitativo } \\
\text { Entrevistas informales y semiestructuadas (40) y de estas } 10 \text { historias. } \\
\text { La tesis pone como centro al cuerpo, como territorio social y culturalmente construido, } \\
\text { como terreno político y como espacio de resistencia económico social, en un contexto } \\
\text { donde las lógicas de mercado capitalista han conseguido desvalorizar las propias vidas } \\
\text { de las mujeres. Presta especial atención a la cooperativa6 como lugar de ejercicio de } \\
\text { liderazgo, como espacio de disputa y relaciones de poder; y el desenvolvimiento de } \\
\text { actividades económico sociales, soporte principal de su economía familiar (p. 8) } \\
\text { Debo reconocer que en estos años, recorriendo este territorio, en una nueva etapa de mi } \\
\text { vida, conseguí interpelarme desde mis entrañas. Descubrí que las formas de los cuerpos } \\
\text { en el cotidiano expresan profundas tristezas a la vez que grandes esperanzas, } \\
\text { laceraciones y violencias, junto a resistencias y ganas de seguir viviendo; pero sin } \\
\text { miedos. Sentí que es posible teñir con nuevos colores aquello que creí saber y asumí como } \\
\text { cierto, volver a desafiarme y seguir apostando por la vida, mi vida, nuestras vidas como } \\
\text { mujeres. Por ello, cobra sentido este recorrido inspirado en diversas formas y colores.(p. } \\
\text { 11) } \\
\text { INTERÉS POLÍTICO SOCIAL }\end{array}$ \\
\hline 2 & $\begin{array}{c}\frac{\text { Masculinidad e }}{\text { identidades }} \\
\underline{\text { simbólicas en }} \\
\text { adolescentes } \\
\text { trabajadores }\end{array}$ & $\begin{array}{l}\text { Alé Sánchez, } \\
\text { Isabel Margarita } \\
\text { Año } 2017\end{array}$ & $\begin{array}{l}\text { Metodología cualitatuva } \\
\text { Entrevista abierta y focus group (16) } \\
\text { Observación. } \\
\text { Por lo descrito, esta investigación plantea analizar las principales características de las } \\
\text { masculinidades y las identidades simbólicas de trabajadores adolescentes de dos } \\
\text { mercados de Lima metropolitana. De esta manera el presente estudio permite describir } \\
\text { las características en que se expresan las masculinidades en adolescentes trabajadores } \\
\text { los cuales limitan el ejercicio de sus derechos. De este modo se podrá contar con elementos } \\
\text { que permitan deconstruir los distintos dispositivos de masculinidad hegemónica que } \\
\text { genera exclusión en dichos adolescentes trabajadores. Con ello se contribuirá a la } \\
\text { construcción de identidades saludables que promuevan relaciones democráticas entre } \\
\text { hombres y mujeres, con la participación de los diferentes actores, entre ellos los propios } \\
\text { adolescentes. (p. 5) } \\
\text { Referencias conceptuales: } \\
\text { Deconstructivismo, identidad de género }\end{array}$ \\
\hline
\end{tabular}




\begin{tabular}{|c|c|c|c|}
\hline 3 & $\begin{array}{c}\underline{\text { Liderazgos }} \\
\text { femeninos en } \\
\text { contextos } \\
\text { mineros. Caso } \\
\text { Tintaya en } \\
\text { Espinar, Cusco }\end{array}$ & $\begin{array}{l}\text { Soria Torres, } \\
\text { Laura Mercedes } \\
\text { Año } 2017\end{array}$ & $\begin{array}{l}\text { Enfoque cualitativo } \\
\text { Entrevistas semiestructuradas a profundidad (20) } \\
\text { Observación participante } \\
\text { Aborda la desigualdad y la invisibilización de la mujer en la toma de decisiones. } \\
\text { Si se considera que prima una tendencia a invisibilizar la presencia de las mujeres en los } \\
\text { espacios de toma de decisiones, resulta primordial iluminar y destacar los procesos de } \\
\text { involucramiento político -formal e informal-de las mujeres en sus entornos sociales. Es } \\
\text { decir, comprender la capacidad de acción y de decisión de las mujeres para } \\
\text { aprovechar las oportunidades sociales, políticas, económicas y culturales } \\
\text { que los proyectos mineros llevan consigo. Urge dejar de considerar a las } \\
\text { mujeres como sujetos pasivos ante el cambio. Nos alienta a ello el entender } \\
\text { que la capacidad de acción y decisión de las mujeres puede tener un efecto } \\
\text { transformador en el contexto rural. Ellas influyen en las instituciones, en los } \\
\text { mercados y en las normas sociales que limitan su capacidad de acción y decisión y sus } \\
\text { oportunidades a nivel personal (p. } 3 \text { ) } \\
\text { Referencias conceptuales: } \\
\text { Espacios de lo cotidiano, estereotipos de género, enfoque de género, liderazgo político, } \\
\text { liderazgos femeninos, sistema patriarcal } \\
\text { INTERÉS POLÍtico SOCIAL }\end{array}$ \\
\hline 4 & $\begin{array}{c}\text { Las otras } \\
\text { víctimas: } \\
\text { violencia y } \\
\text { relaciones } \\
\text { familiares en } \\
\text { Andahuaylas, } \\
\text { durante y } \\
\text { después del } \\
\text { conflicto } \\
\text { armado 1980 - } \\
2000\end{array}$ & $\begin{array}{l}\text { Valer Jaime, } \\
\text { Karina } \\
\text { Margarita } \\
\text { Año } 2017\end{array}$ & $\begin{array}{l}\text { Enfoque cualitativo } \\
\text { Estudio de casos } \\
\text { Entrevistas semiestructuradas (4) } \\
\text { Se focaliza en las conformaciones de las identidades masculina y femenina durante el } \\
\text { conflicto armado. } \\
\text { Para llevar a cabo la presente investigación, se parte del enfoque interpretativo, } \\
\text { identificando y analizando hechos ocurridos en la provincia de Andahuaylas, antes, } \\
\text { durante y después del conflicto armado en las décadas del 8o y el 9o, hasta llegar a } \\
\text { nuestros días. Al mismo tiempo, se estudian los presupuestos filosóficos, ideológicos y } \\
\text { simbólicos de la construcción y reconstrucción de la identidad masculina y femenina en } \\
\text { las zonas de conflicto; la interacción y las formas del "ser mujer"o del "ser varón" del/la } \\
\text { poblador/a andahuaylino/a, entendiendo que éstas construcciones varían de una } \\
\text { cultura, de una época, o de una situación a otra (...) De otro lado, nuestras reflexiones } \\
\text { necesitarán en todo momento de una perspectiva de género, para mostrar los roles } \\
\text { asignados a varones y mujeres y el impacto diferencial que tuvo el conflicto... (pp. } 5 \text { - 6) } \\
\text { Referencias conceptuales: } \\
\text { Construcción, reconstrucción, perspectiva, enfoque, ideología o "teoría" de género. }\end{array}$ \\
\hline 5 & $\begin{array}{l}\frac{\text { El liderazgo de }}{\text { las mujeres }} \\
\text { trabajadoras en } \\
\text { el movimiento } \\
\text { sindical: caso } \\
\text { CGTP, período } \\
\underline{\text { 1995-2011 }}\end{array}$ & $\begin{array}{l}\text { Pisconti Rojas, } \\
\text { Gissela Elizabeth } \\
\text { Año } 2015\end{array}$ & $\begin{array}{l}\text { Enfoque cualitativo } \\
\text { Estudio etnográfico } \\
\text { Entrevistas (45) } \\
\text { Revisión documental } \\
\text { Cuantificación de la participación de mujeres } \\
\text { La tesis aborda el tema del género desde la perspectiva de las diferencias de hombres y } \\
\text { mujeres, la desigualdad y los procesos de reivindicación de la mujer en la CGTP. } \\
\text { La investigación concluye en que estos } 16 \text { años de la CGTP marcan la promoción, } \\
\text { negociación y aprobación de acciones afirmativas inspiradas en el modelo sindical } \\
\text { europeo, adaptadas al modelo peruano y a los intereses colectivos de las mujeres } \\
\text { trabajadoras. Y que a partir de } 2011 \text { comienza una nueva historia para el movimiento } \\
\text { sindical de la CGTP sobre este tema (p. XI) } \\
\text { Según Sonia Montesinos: "El género como concepto constituye un dispositivo } \\
\text { sociocultural a través del cual el mundo se divide para hombres y para mujeres a partir } \\
\text { de las diferencias genitales, con lo cual se producen subjetividades e identidades sociales } \\
\text { distintas que nos parecen naturales. Sin embargo, no se trata de un simple concepto }\end{array}$ \\
\hline
\end{tabular}


ISSN: 2710-0499 ISSN-L: 2710-0480

\begin{tabular}{|c|c|c|c|}
\hline & & & $\begin{array}{l}\text { dentro de las ciencias sociales (...) El género es una epistemología que atraviesa distintas } \\
\text { disciplinas humanas, que nos permite el trabajo conjunto. Pues se trata de deconstruir } \\
\text { nuevos conocimientos que enriquecen las ciencias sociales. La epistemología de } \\
\text { género abre la posibilidad de generar un conocimiento sobre una } \\
\text { construcción cultural que permea las diferentes disciplinas, con la } \\
\text { esperanza de deconstruir este dispositivo que coloca a las mujeres en } \\
\text { desventaja y que impide una comunicación de tipo horizontal entre hombres } \\
\text { y mujeres en la mayoría de las sociedades (p. } 7 \text { ) } \\
\text { Referentes conceptuales: } \\
\text { Construcción, reconstrucción social, teoría, ideología o epistemología de género. } \\
\text { INTERÉS POLÍTICO }\end{array}$ \\
\hline 6 & $\begin{array}{c}\text { La Liberación } \\
\text { de la mujer en } \\
\text { el Perú de los } \\
70 \text { 's : una } \\
\text { perspectiva de } \\
\text { género y Estado }\end{array}$ & $\begin{array}{lr}\text { Barboza } & \text { Tello, } \\
\text { Marco } & \text { León } \\
\text { Felipe } & \\
\text { Año } 2013 & \end{array}$ & $\begin{array}{l}\text { Investigación cualitativa basada en etnografía } \\
\text { Principalmente revisión documentaria } \\
\text { Estudio de la situación de desigualdad de la mujer en los } 70 \\
\text { La tesis busca entender las relaciones de género y Estado, analiza el discurso de las políticas } \\
\text { sobre la mujer de la primera fase del gobierno velazquista y el proceso de revalorización de } \\
\text { la misma, así como los comienzos del movimiento feminista y las concepciones de la } \\
\text { ciudadanía femenina; entendiéndose el género desde esta diferenciación entre hombres y } \\
\text { mujeres dentro de la desigualdad existente y la influencia patriarcalista, poniendo en tela } \\
\text { de juicio la problemática de las mujeres más allá de la esfera doméstica, de la lógica } \\
\text { participatoria y del ámbito educativo cultural. } \\
\text { Así como Fromm, Marcuse también abogaba por arrancar "al Psicoanálisis su espíritu } \\
\text { revolucionario", ya que la represión tenía un origen social, era necesario estructurar un } \\
\text { hombre nuevo, que era cualitativamente un nuevo modo y manera, en la que el hombre } \\
\text { se encontrara y reconociera en este mundo, más allá de lo social, económico y psicológico } \\
\text { el principio de la revolución estaba afirmado, según Marcuse, en la antropología } \\
\text { (Rohrmoser, 1973: 83- 84)" (p. 33) } \\
\text { Referentes conceptuales: } \\
\text { Feminismo, liberación de la mujer, movimiento de mujeres. }\end{array}$ \\
\hline 7 & $\begin{array}{l}\frac{\text { El caso de la }}{\text { AOE en el Perú }} \\
\frac{\text { en el marco de }}{\text { las Políticas de }} \\
\underline{\text { Salud }}\end{array}$ & $\begin{array}{l}\text { Julio Alberto } \\
\text { Zavala } \\
\text { Rodríguez } \\
\text { Año } 2012\end{array}$ & $\begin{array}{l}\text { Enfoque cualitativo } \\
\text { Revisión bibliográfica documental } \\
\text { Se focaliza en los derechos reproductivos de la mujer. El autor está comprometido con la } \\
\text { causa de los derechos sexuales y reproductivos y ha sido un activista en el tema. } \\
\text { La tesis concluye que la discusión del supuesto efecto abortivo no es más que una excusa } \\
\text { de los detractores, para descalificar un método que para ellos tendría efectos perniciosos } \\
\text { en el orden establecido que pretenden preservar (p. VI) }\end{array}$ \\
\hline
\end{tabular}

Cuadro 2: Elaboración propia. 
Según observamos de las dos muestras de tesis, estas son investigaciones de tipo exploratorio o descriptivo, que se enmarcan dentro de los enfoques principalmente cualitativos. Se trata de estudios de casos en donde se hace uso de una metodología que utiliza instrumentos como la entrevista y relatos de vida, así como la revisión documental. A partir de ello se hace un análisis interpretativo y valorativo de las subjetividades, tomando como marco conceptual expresiones posmodernas deconstructivas y de género. $\mathrm{Y}$ asimismo, muchos de los investigadores expresan su compromiso e interés ideológico y político de transformación de la realidad social.

\section{Neocolonialismo del pensamiento posmoderno en la esfera política del Perú}

La influencia de las corrientes, principalmente eurocéntrica y norteamericana, tanto en los estudios culturales, económicos y sociales, así como en la determinación de la ciencia no es ajena a la política. Más aún si este es un objetivo central dentro de las luchas por el poder y control de los medios de educación y difusión de ideas y creencias; particularmente en las ciencias sociales de los últimos tiempos según hemos visto. Antes se tuvo al positivismo, luego al estructuralismo, después al marxismo y ahora al posmodernismo o los discursos de la posverdad. Y se debe tomar en consideración estos aspectos, si es que lo que esta de por medio es el establecimiento de determinados lineamientos ideológicos dentro de los procesos de concientización o reorientación social.

Así, en estas últimas décadas instituciones y organismos internacionales de determinados países de la órbita europea y norteamericana han dirigido muchos recursos para la difusión de políticas públicas, principalmente en las áreas de la educación y la salud. Para ello también han promovido programas de capacitación mediante becas para las élites políticas, sociales, económicas y culturales de los diferentes países que están en su órbita de influencia u objetivos geopolíticos o geoeconómicos y culturales.

Por ejemplo, en los últimos años en el caso del gobierno peruano, la mayoría de funcionarios de los gabinetes del presidente defenestrado Pedro Pablo Kuzynski (PPK) y de su continuador presidente renunciante Martín Vizcarra Cornejo, han tenido estudios en países de la órbita anglófona y eurocéntrica, particularmente Inglaterra, EEUU y los Países Bajos. Y ciertamente las carteras más importantes de economía, educación y salud han estado bajo el control de funcionarios con formación eurocéntrica.

Solo por citar a los presidentes peruanos de los últimos años del siglo XX e inicios del XXI; en el caso de Alberto Fujimori Fujimori, después de sus estudios de pregrado en ingeniería agrónoma en la Universidad Agraria La Molina, hizo estudios de física pura en la Universidad de Estrasburgo en Francia y luego hizo una maestría en ciencias matemáticas en la Universidad de Wisconsin - Milwaukee en Estados Unidos. Por otro lado, Alejandro Toledo estudió economía y administración de empresas en la Universidad de San Francisco, luego hizo en la Universidad de Stanford dos maestrías, una de educación y otra de recursos humanos, y después hizo un doctorado en recursos humanos en esta misma universidad. 
ISSN: 2710-0499 ISSN-L: 2710-0480

En el caso de Alan García Pérez, terminó estudios de abogacía en la Universidad Nacional Mayor de San Marcos (UNMSM) e hizo cursos de doctorado en derecho en la Universidad Complutense de Madrid y de sociología en la Universidad de París; sin embargo, nunca obtuvo el grado. En el caso de Ollanta Humala Tasso, después de su formación militar hizo estudios de maestría en ciencias políticas en la Pontificia Universidad Católica del Perú (PUCP) y después hizo también estudios de doctorado no concluidos en el Instituto de Altos Estudios para América Latina en Francia.

Pedro Pablo Kuczynski (PPK) hizo estudios de licenciatura en política, filosofía y economía en el Exceter College de la Universidad de Oxford en el Reino Unido. Y después hizo una maestría en políticas públicas en la Escuela Woodrow Wilson de asuntos públicos e internacionales de la Universidad de Princeton en los Estados Unidos. Vacado PPK, asumió la presidencia su sucesor Martín Vizcarra Cornejo, este personaje es el único que hizo estudios solo en el Perú, habiendo estudiado ingeniería civil en la Universidad Nacional de Ingeniería (UNI) y luego un diplomado en administración gerencial en la Escuela de Administración de Negocios (ESAN). Finalmente, en este mismo quinquenio, ante el renunciante presidente Martín Vizcarra le sucedió legítimamente, mediante el congreso, el presidente Francisco Sagasti Hochhausler, quien es ingeniero industrial de la UNI e hizo una maestría en ingeniería industrial en la Universidad Estatal de Pennsylvania y después un doctorado en investigación operacional y ciencias de sistemas sociales en la Escuela de Negocios Wharton de la Universidad de Pennsylvania.

En resumen, encontramos que nuestra élite política en su mayoría ha tenido formación en varios de los centros de influencia hegemónicos de Europa y Estados Unidos. Si bien esto puede ser muy bueno para ampliar los horizontes de instrucción y experiencia profesional, también es cierto que dicha formación supone según hemos dicho, un alineamiento en muchos casos con los sistemas de creencias, valores, metodologías y tecnologías desarrollados por los países dominantes o hegemónicos, siendo dichas instrucciones, saberes y prácticas luego implementadas en el Perú desde las diferentes redes institucionales a nivel del Estado y también de la sociedad civil, ya sea en materia económica, social, educativa, cultural, salud pública y etc. Así encontramos por ejemplo en el campo de la economía, una continuidad del pensamiento económico neoliberal introducido por Alberto Fujimori, y que se ha mantenido a lo largo de los diferentes gobiernos democráticos de manera casi inalterable.

En cuanto al Ministerio de Educación, este marcó un cambió en su dirección curricular con el gobierno de PPK a través de su ministra Marilú Martens, quien introdujo una modificación en la currícula escolar planteando el tema de la identidad de género como una construcción social. Esto generó un debate y conflicto entre diferentes agrupaciones de la sociedad civil y el Estado por las posibles consecuencias de ello (desarrollo de la educación desde la óptica de diversidad de géneros). 
Y en lo referente al Ministerio de Salud, de igual manera con el gobierno de PPK y después Vizcarra, se empezó una campaña de introducción de la "teoría", enfoque o ideología de género (según la perspectiva del debate) que se plasmó en el cambio y orientación del discurso institucional y de la asignación de recursos ya no solo para proveer de retrovirales a las personas con VIH sino para la asistencia, consejería y tratamiento de los programas de hormonización para el cambio de género (resolución ministerial No 980 - 2016 / Minsf).

Por otra parte, las formas de receptación de nuevos cuadros para su formación y alineamiento, dentro de un esquema de "intercambio cultural", se realiza desde hace décadas con programas de becas de estudios financiados por los países hegemónicos en el mundo occidental, principalmente de Europa; siendo Inglaterra, Francia, Alemania y los Países Bajos los más importantes.

El objetivo de dichos programas tiene un horizonte geopolítico y geoeconómico dentro de los planeamientos estratégicos e ideológicos de las potencias. No solo se trata de hacer intercambios estudiantiles y aprender de otras experiencias culturales, sino de tener un amplio margen de influencia sobre los países beneficiados a través de sus élites intelectuales y económicas. Tal es así que las élites intelectuales de dichos países, especialmente subdesarrollados, puedan ser formados bajo los principios, valores, saberes y prácticas impartidos por las potencias. Esto incluye sus formas de pensar y actuar, incluyendo sus idiomas como instrumentos o vehículos junto con el marco de creencias, estilos de vida e intereses compartidos de sus sociedades e instituciones. Así podrán adaptarse a los marcos de referencia política, económica y cultural de los centros dominantes. Esto podemos inferir por ejemplo, de la formación y relaciones o dinámicas políticas, económicas, educativas, culturales y sociales que han tenido nuestros diferentes jefes de Estado en las últimas décadas.

\section{CONCLUSIONES}

Es importante abordar el estudio de estos fenómenos sociales, económicos y culturales, particularmente el neocolonialismo en sus diferentes niveles; pues están enmarcados dentro de una visión global, geoeconómica y estratégica que afectan los intereses de los pueblos.

Puede decirse que el desarrollo de las ciencias sociales en el Perú, al igual que en otros campos del saber, estos fueron importados en su desarrollo. Así, la antropología, la sociología, la historia y la arqueología; fueron campos de estudio e investigación introducidos en el mundo latinoamericano, y particularmente en nuestro país, por estudiosos extranjeros interesados en nuestra realidad.

El rastro neocolonial puede observarse en la influencia epistemológica que provenía del positivismo, el estructuralismo y después del marxismo. En la década de los ochenta, en el caso del marxismo por ejemplo, este se impartía en diferentes universidades estatales, en cursos tales como materialismo dialéctico e histórico y otros. Mientras que en las universidades particulares 
ISSN: 2710-0499 ISSN-L: 2710-0480

o privadas se daba preferencia a cursos con enfoques desde las perspectivas filosóficas, económicas y políticas liberales o neoliberales.

Asimismo, desde fines de siglo XX y comienzos del XXI se ha ido introduciendo progresivamente el pensamiento posmoderno en el campo de las ciencias sociales en el Perú. De esta forma, en la dinámica neocolonial contemporánea, a parte de las relaciones económicas, comerciales y culturales asimétricas de dependencia; en los campos intelectuales se promueven los estudios en el exterior para aprender y adaptarse a las nuevas visiones epistemológicas y tecnológicas. $\mathrm{Y}$ junto con ello se asimilan sistemas de creencias y valores que luego se podrán aplicar a su regreso, reproduciendo y normalizando de este modo una nueva conciencia o relaciones de alienación cultural. Así los educandos de las universidades bajo estas influencias continúan realizando sus estudios bajo estos nuevos parámetros, particularmente en el caso de las ciencias sociales, con preponderancia cualitativa y crítica con interés de tipo social y político.

Esto podemos verlo por ejemplo en diferentes tesis de investigación; reproduciéndose de esta forma sus narrativas, ideologías, sistemas de creencias, métodos y tecnologías. Así, el neocolonizado, asume y expresa estas convicciones, estilos, creencias y lineamientos importados de acuerdo a los vaivenes de los espacios sociopolíticos, culturales, "académicos” y económicos dominantes. Esto también puede inferirse de las orientaciones, dinámicas y relaciones políticas, económicas, educativas y culturales de los diferentes jefes de Estado de las últimas décadas en el Perú.

Ciertamente, el conocimiento y experiencia obtenida por dichos estudios e intercambios deberían ayudar al desarrollo de una propia visión y desarrollo epistemológico, científico, metodológico y tecnológico; sin embargo, todavía se encuentra pendiente como tarea lograr esa emancipación.

\section{REFERENCIAS BIBLIOGRÁFICAS}

Ale, I. (2017). Masculinidad e identidades simbólicas en adolescentes trabajadores. Tesis para optar grado de Magíster en Género, Sexualidad y Políticas Públicas. Unidad de Posgrado, Facultad de Ciencias Sociales, Universidad Nacional Mayor de San Marcos, Lima, Perú.

Altbach, P.G. (1971). Education and Neocolonialism: A Note. Comparative Education Review, pp. 237-239.

Barboza, M. (2013). La Liberación de la mujer en el Perú de los 7o's: una perspectiva de género y Estado. Tesis para optar grado de Magíster en Género y Desarrollo. Unidad de Posgrado, Facultad de Ciencias Sociales, Universidad Nacional Mayor de San Marcos, Lima, Perú.

Berger, P. y Luckmann, T. (1985) La construcción social de la realidad, Amorrortu editores, Buenos Aires. Burga, M. (2005) Historia y antropología en el Perú (1980-1998): tradición, modernidad, diversidad y nación. Recuperado el 6 de junio de 2018, de https://sites.fas.harvard.edu/ icop/manuelburga.html

Britto, L. (2012) India y américa Latina, colonización, descolonización y no alienación. En: FAIA. VOL. I No III. Cieza, K. (2016) Representaciones sociales de la maternidad y los significados que le asignan las mujeres jóvenes universitarias de estratos medios bajos de Lima Metropolitana en la construcción de la feminidades e identidades femeninas. Tesis para optar el grado de Magistra en estudios de género. Escuela de Posgrado. Pontificia Universidad Católica del Perú. Lima, Perú. 
Cunow, H. (1929) Las comunidades de aldea y de marca del Perú antiguo. Biblioteca de Antropología Peruana, 2. Paris: J. Jiménez Editores.

Cunow, H. (1929) El sistema de parentesco peruano y las comunidades gentilicias de los incas. Paris: Imprenta de "Le Livre Libre".

Cunow, H. (1933) La organización social del imperio de los incas (investigación sobre el comunismo agrario en el antiguo Perú). Lima: Librería y Editorial Peruana.

Denzin, N. K. \& Lincoln, Y. S. (2005) The Sage Handbook of Qualitative Research. Third Edition. Thousand Oaks: Sage Publications, Inc. Introduction. The Discipline and Practice of Qualitative Research, pp. 113.

Dussel, E. (2001). Eurocentrismo y modernidad (Introducción a las lecturas de Frankfurt), Capitalismo y geopolítica del conocimiento: el eurocentrismo y la filosofía de la liberación en el debate intelectual contemporáneo. Mignolo (comp). Buenos Aires: Ed. El Signo.

Dussel, E. (2013). Discurso de presentación del Dr. Enrique Dussel ante la comunidad de la UACM, Recuperado el 17 de febrero del 2021 de https://filosofiauacm.wordpress.com/2013/o3/11/discurso-del-drenrique-dussel-como-rector-interino-de-la-uacm/

Dussel, E. (2015) Filosofías del Sur. Descolonización y Transmodernidad. México: Akal.

García, R. (2017) Violación y masculinidad: representaciones de lo masculino en varones recluidos por ejercer violencia sexual en el establecimiento penitenciario de Cañete. Tesis para optar el grado de Magistra en estudios de género. Escuela de Posgrado. Pontificia Universidad Católica del Perú. Lima, Perú.

Gupta, A. y J. Ferguson (1997) Discipline and practice: The field as site, method, and location in anthropology. In: Akhil Gupta and James Ferguson (eds.) Anthropological locations: Boundaries and grounds od a field science. Berkeley: University of California Press, pp $1-47$.

Ferguson, J. (1997) "The Country and the City on the Copperbelt". En: Culture, Power, Place. Explorations in Critical Anthropology, Akhil Gupta and James Ferguson (eds.), Durham and London: Duke University Press, pp. 137-153.

Haag, D. (2011). Mechanisms of Neocolonialism: Current French and British in Cameroon and Ghana. Barcelona: Institut Català Internacional Per la Pau. Consultado el 20.02.21 Disponible en línea https://papers.ssrn.com/sol3/papers.cfm?abstract_id=2033138

Lander, E. (comp.) (2000) La colonialidad del saber: eurocentrismo y ciencias sociales. Perspectivas latinoamericanas. Buenos Aires, Argentina: Consejo Latinoamericano de ciencias sociales CLACSO.

León, E. (2013) Un siglo de investigación arqueológica alemana en el Perú. Historia de la Arqueología en el Perú del siglo XX. En: Instituto francés de estudios andinos IFEA, Lima, pp $333-359$.

Macías, K.C. (2015). El neocolonialismo en nuestros días: La perspectiva de Leopoldo Zea. En: Universitas Philosophica, 32(65), pp. 81-106.

Martín Serrano, M. (2009). La Teoría de la Comunicación, la vida y la sociedad. Intercom. En: Revista Brasileira de Ciências da Comunicação, 32(1), pp. 245-257.

Mejía, J. (2005) El desarrollo de la sociología en el Perú. En: Sociologías, 7 (14), 302-337.

Menéndez, E. (2018) Colonialismo, neocolonialismo y racismo: el papel de la ideología y de la ciencia en las estrategias de control y dominación. México, UNAM, 156 p.

Métraux, A. (1983) Les Incas. París: Le Seui.

Mignolo, W.D. (2007). El pensamiento decolonial: desprendimiento y apertura. S. Castro Gómez \& R. Grosfoguel. (Coords.), El giro decolonial. Bogotá: Siglo del Hombre Editores.

Ormachea, I. (2018) Masculinidades en los conflictos socioambientales: el caso conga. Tesis para optar el grado de Magíster en estudios de género. Escuela de Posgrado. Pontificia Universidad Católica del Perú. Lima, Perú.

Ortiz, C. (2004). Proceso de descolonización del imaginario y del conocimiento en América Latina. Poéticas de la violencia de la crisis. Lima: Universidad Nacional Mayor de San Marcos.

Ortiz, C. (2011). Género, colonialidad del poder, conocimiento y las políticas de igualdad hoy. Seducción, género y poder en Dioses y hombres de Huarochirí y la Nueva crónica y buen gobierno. En Revista de Sociología, Fac. de CC.SS. de la UNMSM, Lima, $\mathrm{N}^{0}$ 21, pp. 185-201. 
ISSN: 2710-0499 ISSN-L: 2710-0480

Peña, E. (2017) Participación y representación subjetiva de mujeres organizadas en contextos de conflicto y postconflicto. Tesis para optar el grado de Magíster en estudios de género. Escuela de Posgrado. Pontificia Universidad Católica del Perú. Lima, Perú.

Pérez, E. (2020). Las formas y colores de los cuerpos en el cotidiano de mujeres cooperativistas de la selva central: persona, economía social y política. Tesis para optar el grado de Magíster en Género, Sexualidad y Políticas Públicas. Unidad de Posgrado, Facultad de Ciencias Sociales, Universidad Nacional Mayor de San Marcos, Lima, Perú.

Pisconti, G. (2015). El liderazgo de las mujeres trabajadoras en el movimiento sindical: caso CGTP, período 1995 - 2011. Tesis para optar grado de Magíster en Género y Desarrollo. Unidad de Posgrado, Facultad de Ciencias Sociales, Universidad Nacional Mayor de San Marcos, Lima, Perú.

Quijano, A. (2000) Colonialidad del poder, eurocentrismo y América Latina. En: Edgardo Lander, La colonialidad del saber: eurocentrismo y ciencias sociales. Perspectivas latinoamericanas, Buenos Aires, Clacso.

Quijano, A. (2000) Colonialidad del poder y clasificación social. En: Journal of world-systems research, VI, 2, summer/fall 2000, pp. 342-386

Quijano, A. (2010) La crisis del horizonte de sentido colonial/moderno/eurocentrista, En Casa de las Américas, núm. 259, 2010, pp. 4-15.

Quijano, A. (2014) Colonialidad del poder, globalización y democracia. En: Cuestiones y horizontes: de la dependencia histórico-estructural a la colonialidad/descolonialidad del poder. Buenos Aires: CLACSO.

Quijano, A. (2014) Colonialidad del poder, eurocentrismo y América latina. En: Cuestiones y horizontes: de la dependencia histórico-estructural a la colonialidad/descolonialidad del poder. Buenos Aires: CLACSO.

Rivet, P. (2002) Los orígenes del hombre americano. Trad. de José Recaséns y Carlos Villega, $3^{\mathrm{a}}$ ed. México: FCE, $198 \mathrm{p}$.

Rodríguez, E. (2017) Reconstrucción de las memorias colectivas de los grupos de lesbianas feministas de Lima en el periodo 1984-2014. Tesis para optar el grado de Magistra en estudios de género. Escuela de Posgrado. Pontificia Universidad Católica del Perú. Lima, Perú.

Salazar B, A. (1968) ¿Existe una filosofía de nuestra América? México. Siglo XXI editores. Recuperado de http://revistasolar.org/wp-content/uploads/2017/12/Existe-una-filosofia-en-nuestra-America-.pdf

Soria, L. (2017). Liderazgos femeninos en contextos mineros. Caso Tintaya en Espinar, Cusco. Tesis para optar grado de Magíster en Género y Desarrollo. Unidad de Posgrado, Facultad de Ciencias Sociales, Universidad Nacional Mayor de San Marcos, Lima, Perú.

Stocking, G. Jr. (1986). History of anthropology, Volume 4. Malinowski, Rivers, Benedict and others: Essays on culture and personality. Madison: University of Wisconsin Press, $240 \mathrm{p}$.

Stocking, G. Jr. (1989) Romantic motives: Essays on anthropological sensibility. Madison: University of Wisconsin Press, 280 p.

Tantaleán, H. (2016) Una historia de la arqueología peruana. Lima, Perú: Instituto de estudios peruanos IEP, Universidad San Francisco de Quito.

Valer, K. (2017). Las otras víctimas: violencia y relaciones familiares en Andahuaylas, durante y después del conflicto armado 1980 - 2000 . Tesis para optar grado de Magíster en Género y Desarrollo. Unidad de Posgrado, Facultad de Ciencias Sociales, Universidad Nacional Mayor de San Marcos, Lima, Perú.

Vargas, J. (2005). Neocolonialismo, resistencia, crisis y transformación del estado. En: Revista internacional de ciencias sociales y humanidades, 15(2), pp. 155-183.

Zavala, J. (2012). El caso de la AOE en el Perú en el marco de las Políticas de Salud. Tesis para optar grado de Magíster en Género y Desarrollo. Unidad de Posgrado, Facultad de Ciencias Sociales, Universidad Nacional Mayor de San Marcos, Lima, Perú.

Zea, L. (1945) En torno a una filosofía americana. El Colegio de México. En Jornadas 52. México.

Zea, L. (1974) Dependencia y liberación en la cultura americana. Joaquín Mortiz, México.

Zea, L. (1988) Ideas en torno de Latinoamérica. 2 Tomos, UNAM/UDUAL. 